produced in this way. We are sure that urgent warnings are essential to ensure that suitable folate supplements are given to patients fed intravenously.

Charles A J WARdrop

L E HUGHES

G B TENNANT

S J LEINSTER

University Department of Surgery,

Welsh

Wardrop, C A J, et al, Lancet, 1975, 2, 640

Wardrop, C A J, et al, British fournal of Haematology 1977, 37, 521 . et al, British fournal of Haematology mith,

\section{Nutrition and the cancer patient}

SIR,-We read with interest your leading article (23 September, p 846) and welcome the new awakening interest in the problem of cancer cachexia in man. While determination of the major factors which contribute to its pathogenesis will necessitate in vivo studies, ${ }^{1}$ a suitable experimental model system may yield useful clues. However, at the present time we feel that the experimental models currently available are inadequate. Those mentioned in your article ${ }^{34}$ relate to studies with transplantable anaplastic animal tumours, as do numerous other studies which can be found in the literature. These experimental models are straightforward to work with and provide the experimenter with quick and reproducible results. Their relevance to cachexia in man can, however, be questioned, since these tumours grow rapidly and may comprise as much as $40^{\circ}{ }^{\circ}$ of the final body weight of the animal, a tumour burden which is rarely encountered in the cancer patient. Only when tumours reach this relatively massive size do animals demonstrate any loss of weight or other symptoms of cachexia.

In a recent report Lundholm et al, have described similar metabolic abnormalities in liver and muscle tissue from cancer patients and from tumour-bearing animals, which they suggest may be related to the development of cachectic symptoms in man. While these results are clearly significant, the authors fail to relate their findings to any cachectic symptoms in the group of patients examined, and indeed control and tumour-bearing animal groups demonstrated a similar body weight at the time of metabolic studies.

Recently we have developed an experimental model of cancer cachexia utilising the immunosuppressed mouse. A hypernephroma was apparently totally removed at nephrectomy from a patient who had suffered $25 \mathrm{~kg}$ weight loss in the two months preceding surgery. It was grown as a xenograft in immunosuppressed mice. Over a period of six weeks, although this tumour grew slowly, the animals became cachectic, losing up to $30^{\circ}$ of their initial body weight. On death the tumour, which failed to metastasise, comprised less than $5 \%$ of the final body weight of the animal. Both the tumour and the animal are considered to be free of bacterial and viral contamination and present studies have indicated that nutritional depletion does not play a major role in the onset of progressive weight loss. It would therefore appear likely that this tumour may cause cachexia in mice by a mechanism other than one of simple malnutrition. The precise mechanism remains to be established but elaboration of some humoral factor or factors by the tumour seems possible. Current work is in progress to examine this possibility.

We believe that the immunosuppressed animal presents an ideal model for experimental studies of the aetiology of cachexia induced by human tumours and that it bears a closer relation to the clinical condition than do other experimental animal tumour models currently available.

A J Strain

G C EASTY

Unit of Human Cancer Biology,

Ludwig Institute for Cancer Research

(London Branch),

Royal Marsden Hospital

Sutton, Surrey

Warnold, I, et al, Cancer Research, 1978, 38, 1801.

Jasani, B, et al, British fournal of Cancer, 1978, 38, 287. Calman, K C, and McAllister, R A, British fournal of Cancer, 1975, 32, 247.

ratt, A W, and Putney, F K, fo

Lundholm, K, et al, Cancer, 1978, 42, 453.

\section{Clarinettist's cheilitis}

SIR,-I read with interest my colleague Dr M G C Dahl's letter (7 October, p 1023) on flautist's chin, which reminded me of three patients I have seen over the past five years with an apparent eczematous dermatitis confined to the median area of the lower lip, in each case exactly underneath the reed of the clarinet. The patients came from different military bands and had been employed as clarinettists on average for over five years. The lesions had been present when seen for up to two to three months.

Extensive patch-testing gave no positive results, but the significant part of the history was that the lesions had appeared in all three cases since the patients had undertaken extra "moonlighting" engagements with pop groups, etc, in addition to their normal military duties. Two patients recovered completely on reversion to normal military duties only and the third understandably failed to attend for follow-up when it was implied that his employers, the Army, might regard his skin lesions as self-inflicted.

T C HrNDSON

Department of Dermatology,

Royal Infirmary,

Sunderland, Tyne and Wear

\section{Flautist's chin}

SIR, - The letter on flautist's chin by Dr M G C Dahl (7 October, p 1023) prompts me to make the following comments.

I am sure that he is right in attributing the condition to wetting of the skin below the lower lip, especially in a sebaceous subject. The resulting slipperiness causes an insecure embouchure, which the player tries to counteract by increasing the pressure of the instrument against the skin, and also by frequent tentative adjustments which produce an element of mechanical irritation. Thus flautist's chin is brought into line with fiddler's neck, trumpeter's lip, etc.

I think $\mathrm{Mr}$ Dahl is probably wrong in assuming that the main or only source of the moisture is saliva. Blowing a saliva spray is incompatible with producing a pure tone, and the player avoids it. More likely causes are breath condensate, which is unavoidable, and perspiration in anticipation of a difficult or exposed passage. To the extent that perspira- tion is involved the local use of an antiperspirant would be worth trying

Since the war, metal flutes with their more brilliant tone have become relatively more popular than wooden ones, especially for orchestral playing. On account of the cost of silver and gold, these flutes are mostly alloy. There is therefore the possibility that the condition complained of is due to a sensitivity to nickel, chromium, or some other constituent of the alloy. The easiest way to check on this would be for the player to borrow a cocuswood, silver, or vulcanite flute for a few weeks. For a man, as I was taught many years ago, the solution of the problem is simple. He grows an unobtrusive little goatee below the lower lip, and thus interposes a layer of dry bristle and air between the mouthpiece and the skin. The embouchure can then be made further secure, if necessary, by a light application to the bristles of resin readily available from a string player.

L D GARDNER

West Baldwin

Isle of Man

Medical and dental problems of musical instruments

SIR,-A day before I read the interesting report by Dr M G C Dahl (7 October, p 1023) of a case of "flautist's chin" I was asked by a 40-year-old male amateur clarinet player if anything could be done about the ulceration of his labial mucosa associated with playing this instrument. The answer is yes: a thin, custom-built mouthguard made of polyvinyl or acrylic resin covering the 6-8 lower anterior teeth can be made to give the player comfort, if simple smoothing of the sharp incisal edges does not suffice.

The dental problems arising from playing musical instruments were well discussed in series of 12 articles by Porter, which have been republished as a monograph. ${ }^{1}$

JOHN D JAGO

Department of Dentistry,

Brisbane, Australia

Porter, M M, Dental Problems in Wind Instrumen

Playing. London, British Dental Association, 1968.

Treatment of childhood cancer: effects on gonads

SIR,-We were interested in your leading article (16 September, p 785) concerning gonadal function following the treatment of cancer in childhood. One point worthy of comment is the suggestion that the vulnerability of the testis to cytotoxic damage may be critically dependent on age and pubertal status. One of the major reasons for the development of this hypothesis has been the observation by several groups ${ }^{12}$ that basal gonadotrophin levels of prepubertal boys treated with cytotoxic drugs were not abnormally elevated. However, study ${ }^{3}$ of patients who received testicular irradiation in prepubertal life has revealed grossly reduced sperm counts and elevated serum folliclestimulating hormone levels when these individuals achieve adulthood but essentially normal basal gonadotrophin levels while they remain prepubertal. This suggests that estimation of the basal gonadotrophin levels is an unreliable method of predicting testicular damage in prepubertal life when that damage predominantly affects the tubular elements. 